\title{
Yang Datang Setelah Hujan: Sains-Agama Penerang Kegelapan*
}

\author{
Tarmizi Abbas \\ Institut Agama Islam Negeri (IAIN) Sultan Amai Gorontalo \\ Email: abbastarmizi@gmail.com \\ Ismail Suardi Wekke \\ Sekolah Tinggi Agama Islam Negeri (STAIN) Sorong \\ Email: iswekke@gmail.com
}

\begin{abstract}
ABSTRAK
Sains dan agama, terang diketahui, masih sering diperdebatkan. Agama dikenal menjadi sebuah ajaran yang kaku, eksklusif, dan menolak perubahan; sedang sains dimahfumi merupakan sebuah pencerahan. Dengan menggunakan teori integrasi Ian G. Barbour dan pendekatan Whiteheadian, tulisan ini akan memperlihatkan bahwa sebenarnya sains dan agama adalah dua variabel yang saling menopang satu sama lain. Hanya sikap-sikap keagamaan lah yang membuat keduanya menjadi saling menolak. Selain itu, tulisan ini bertujuan untuk menjernihkan pemahaman publik bahwasanya, agama sebenarnya bersumber dari pengtahuan.
\end{abstract}

Kata Kunci: Agama, sains, sikap keagamaan

\section{Pendahuluan}

BARANGKALI benar, peradaban telah bergerak pesat. Samar-samar masih terdapat di lingkungan kita (Indonesia) 15 tahun yang lalu, untuk belajar perlu kejarkejaran dengan lilin. Butuh antre berjam-jam di wartel (warung telepon) untuk sekadar berkata "apa kabar" kepada keluarga yang jauh. Atau, perlu menggenapkan koin seratusan sebanyak lima keping untuk mendengar cerita orang tua di seberang kompleks perumahan selama beberapa menit lewat telepon umum. Jelang idul fitri pajangan kartu lebaran berderet di kantor pos. Dikirim untuk saling menyapa di hari yang suci. Tapi hal-hal semacam ini sudah selesai. Saat ini, orang-orang bahkan tak perlu lampu untuk belajar lantaran mereka punya gadget yang siap memberi informasi tanpa batas; tak perlu perlu telepon umum untuk "say hello", sebab platform bernama Facebook, Instagram, Twitter, Whattsapp, dll., bahkan memungkinkan "panggilan video" agar interaksi terjadi lebih nyata; juga, ada mungkin orang-orang tidak butuh lagi dawuh para ustaz dan Kyai, karena Youtube-sebuah media online videomemungkinkan orang-orang belajar agama secara instan. Cukup dengan layanan pesan

\footnotetext{
${ }^{*}$ Seminar Rencana Alih Status STAIN Sorong menjadi IAIN Sorong, Jakarta 14 s.d. 16 November 2019.
} 
singkat, hari ini bahkan difasilitasi dengan aplikasi seperti Whastup, kabar bahkan bisa terkirim setiap saat.

Sains yang menciptakan hal demikian. Tapi perubahan yang dikehendaki sains tidak terjadi secara radikal. Sains itu seperti roda bergerigi yang memungkinkan jarum jam tetap bergerak maju. Perlahan, namun pasti tak ada satu pun yang mampu menahannya. Dan tak terasa, putaran jam itu telah (dan akan terus) memperbaiki segalanya: perkembangan pesat dalam bidang komunikasi, transportasi, kesehatan, pangan, hukum, dan kemanusiaan telah sebaik yang diharapkan manusia. Penerapan sains dalam dunia modern telah memungkinkan kehidupan manusia menjadi lebih sehat, lebih nyaman, dan lebih aman. Armahedi Mazhar bahkan menyebut, "sains merupakan karunia pada manusia yang tak tertandingi sepanjang zaman"1

Sains memastikan tak butuh lagi waktu berbulan-bulan untuk mengarungi lautan agar bisa sampai ke tempat yang kita inginkan. Lewat jalur udara, orang-orang dari dataran Asia hanya butuh waktu 8-10 untuk sampai di Amerika, dan 4-5 jam saja ke Eropa dan Afrika. Sains juga membuat semua serba terhubung, jari-jari memiliki kontrol, akses tak terbatas. Di dalam perkembangan itu, informasi juga membanjir. Masyarakat bisa memperoleh berita kemenangan presiden, bantuan-bantuan kemanusiaan, bencana alam, peperangan, kekerasan, pencurian, dan tragedi demi tragedi-yang bahkan ditampilkan secara live.

Dalam sejarah umat manusia, sains adalah cahaya. Ia melenyapkan bentukbentuk takhayul, jimat, dan berbagai hal mistis". ${ }^{2}$ Bagi sains, lebih baik memberi cukup waktu untuk melakukan diagnosa ketimbang mempercayai sesuatu hal yang terjadi secara kebetulan. Para saintis membaca tanda yang bertentangan dan silang-selimpat; untuk selanjutnya ditarik beberapa variabel sebagai dasar dalam mengambil keputusan. Itu sebabnya mengapa sains menolak hal-hal mistis untuk dijadikan sebagai sandaran.

Tentu tidak mudah memberi jalan agar sains bisa diterima secara luas. Setelah lenyaplah takhayul, musuh sains yang sesungguhnya adalah agama. Di dalam agama, terbesit keyakinan utuh atas kekuatan Adikodrati yang mengatur jalannya alam semesta. Sedang dalam sains, keraguan terhadap pencipta akan selalu menghantui. Sains bergerak dengan semangat objektif, agama cenderung otoritatif. Adapun bagi para saintis, agama menyebabkan orang-orang berhenti berpikir kritis. Sedang bagi para agamawan, perubahan-perubahan yang dihasilkan sains membikin mereka tidak bisa menjalankan agama dengan nilai-nilai yang murni. Akibatnya, sepanjang peradaban, terjadi semacam perpotongan yang cukup tajam di antara sains dan agama.

Seiring dengan perjalanan sejarah, beberapa abad setelah renaisans, revolusi sains, diikuti oleh revolusi industry yang tidak berhenti di fase ketiga bahkan bergerak

${ }_{1}^{1}$ Mazhar, Armahedi, Manusia, Alam dan Tuhan: Menyepadukan Sains dan Agama, sebuah pengantar dalam buku "Ian G. Barbour: Menemukan Tuhan dalam Sains Kontemporer", Bandung: Mizan, 2005, h. 9.

${ }^{2}$ Carl Sagan, The Demon Haunted World: Sains Penerang Kegelapan, (Jakarta: Kepustakaan Populer Gramedia, 2018), h. 6 
ke fase kelima, munculnya kecerdasan buatan (AI), perang nuklir, neurosains, hingga melimpahruahnya informasi, wacana sains benar-benar bergerak begitu mutakhir. Sebuah pergerakan yang memiliki pengaruh besar terhadap perubahan struktur dan kondisi ekonomi, sosial, dan politik dunia. Terdapat satu pertanyaan yang menjadi pokok bahasan artikel ini "bagaimana kesanggupan sains memengaruhi agama?"

\section{Metode}

Secara umum, penelitian ini merupakan sebuah tinjauan eksplanatoris dengan menggunakan teori Ian G. Barbour dan Whitehead dalam menjabarkan hubungan antara sains dan agama. Dalam pandangan Barbour, hubungan antar sains dan agama dapat dijelaskan melalui empat varian, yakni: konflik, independensi, dialog, dan integrasi. Dalam kaitannya dengan sains-agama, Barbour memilih varian integrasi untuk menjabarkan bagaimana agama dan sains sebenarnya saling menopang.

\section{Tiga Catatan Penting tentang Sains-Agama}

Abad ke 21 adalah era yang cukup pelik untuk orang-orang beriman. Kepelikan yang di antaranya diajukan untuk menyoal status agama; apakah nilai-nilai yang dikandungnya masih relevan jika diperhadapkan dengan modernitas dan sains kontemporer yang tercermin dalam bioteknologi, ekonomi internasional, algoritma, kecerdasan buatan, neurosains, pemanasan global, sistem robotik yang mengekang, perang cyber, hingga digital dictatorship 3 (seperti China dan Korea Utara)? Dapatkah visi agama yang transendental membebaskan manusia dari sumur-sumur kekecewaan dan kebingungan yang dilepaskan secara membabi buta di era post-truth?

Di tahun 1784, Imanuel Kant menulis sebuah esay yang begitu menarik tentang "Apa itu pencerahan?". Kant membuka tulisannya dengan menyatakan, "pencerahan, adalah apa yang membebaskan manusia dari ketidakdewasaan yang dibuatnya sendiri," yang malas dan pengecut, dan begitu berpasrah terhadap 'dogma dan formula' agama dan politik.4 Bagi Kant, "Pencerahan” berarti Sapere Aude! "Berani berpikir sendiri!" Dan untuk sebuah pencerahan, kebebasan berpikir dan berbicara adalah harga mati. Sains menghendaki itu. Sebab oleh fisikawan David Deutsch dalam The Beginning of Infinity, "kebebasan bertindak dan berpikir secara saintifik menghendaki perubahan

3 Term Digital Dictatorship atau yang disebut dengan Kediktatoran Digital adalah sebuah kepemimpinan diktator gaya baru yang menempatkan pemerintah sebagai pengontrol apapun yang dilakukan oleh masyarakat lewat teknologi. Gaya kepemimpinan ini, oleh Yuval Noah Harari (Lihat dalam 21 Century, atau Homo Deus) memungkinkan Pemerintah memiliki akses terhadap pesan, record (catatan individual), transaksi, rekam jual beli dan seluruh aktifitas masyarakat. Selengkapnya, Kediktatoran Digital dapat juga diakses pada: https://www.economist.com/leaders/2016/12/17/chinasdigital-dictatorship.

4 Steven Pinker, Enlightenment Now (Pencerahan Sekarang Juga): Membela Nalar, Sains, Humanisme, dan Kemajuan, (Manado: Penerbit Gloalindo, 2019), h. 8. 
secara signifikan terhadap moral, kebijakan, dan pemahaman manusia di masa depan". 5 Dengan demikian, menolak sains berarti secara tidak langsung membuat manusia kembali lagi dalam sumur-sumur kejahilan mereka.

Di abad pertengahan, keputusan para pemimpin-pemimpin religius adalah mutlak. Sola Scriptura! Sebuah anjuran untuk mengajak masyarakat kembali "hanya" pada al-Kitab. ${ }^{6}$ Ketika pertikaian antara sains dan agama terjadi begitu hebat, alhasil para saintis klasik dengan cermat menemukan bahwa agama, lewat gereja-gereja, terlalu kaku dan tidak mampu membuka diri terhadap perubahan. Lalu seketika situasi berbalik begitu cepat: sains mendapat tempat dan agama perlahan mulai ditinggalkan. Orang-orang lebih memilih memberi obat-obatan daripada berdoa dan meminta pandangan para pendeta. Teks-teks suci memang berpengaruh pada abad-abad pertengahan, tapi bagaimanapun juga ayat-ayat kanonik tidak mampu membimbing manusia menyelesaikan hal-hal yang begitu kompleks saat ini.7

Benar bahwa, dibanding agama, "sains" meminjam Carl Sagan, "memiliki kesadaran untuk terus melakukan kritik terhadap sesuatu meskipun harus melalui jalan terjal dan berbatu. Sedang agama, tetap dalam personanya yang eksklusif". 8 Agama memiliki klaim otoritas, Nabi-nabi pembawa pesan, serta ayat-ayat yang mengukuhkan keyakinan seseorang. Sedang sepanjang waktu, kita terus melihat bahwa sains tidak pernah takut untuk mengakui kegagalan. Sains memiliki semacam sistem untuk mengoreksi diri. Karena bagi sains, gagal berarti satu langkah menuju "kejelasan" masa depan. Sains, adalah apa yang pernah diutarakan lantang oleh Kant, "Sapere Aude! Berani berpikir sendiri!

Lebih dalam, Yuval Noah Harari memetakkan tiga hal penting yang mendasari mengapa agama dianggap "gagal" saat ini, yakni: (1) Masalah teknis; (2) masalah kebijakan, dan; (3) masalah identitas. Harari berpendapat, pertama, agama-agama tradisional sebagian besar tidak relevan dengan masalah teknis yang dihadapi oleh umat manusia hari ini. Di era pra-modern, agama memang memainkan peran yang begitu siginifkan terhadap pertanian masyarakat Kristiani di eropa. ${ }^{9}$ Kalender ilahi menentukan kapan menanam dan memanen, sedangkan ritual di kuil-kuil memastikan curah hujan dan perlindungan terhadap hama.10 Atau dalam hal kesehatan, para imam yang biasanya menjadi penyambung lidah Tuhan, juga merangkap sebagai tabib. Namun saat ini, hal-hal demikian telah diambil alih oleh para botanis, para pengamat

5 Ibid, h. 10.

${ }^{6}$ Graham E. Fuller, Dunia Tanpa Islam: Apa Jadinya Dunia Tanpa Isla? Sebuah Narasi Sejarah Alternatif, (Bandung: Mizan, 2014), 30.

7 Yuval Noah Harari, 21 Lessons: 21 Adab Untuk Abad ke 21, (Globalindo: Manado, 2018), h. 5.

8 Carl Sagan, The Demon-Haunted World: Sains Penerang Kegelapan, (Jakarta: Kepustakaan Gramedia, 2018), h. 32.

9 Karen Armstrong, Sejarah Tuhan: Kisah Pencarian 4000 Tahun Agama-agama Dunia, (Bandung: Mizan, 2015), h. 176.

10 Ibid, h. 177. 
cuaca, dan dokter-dokter ahli, lantaran para pemeluk agama berkeyakinan bahwa modernitas membuat nilai-nilai yang terkandung dalam agama menjadi tidak otentik.

Kedua, dalam hal kebijakan-kebijakan global, agama selalu menempati posisi sebagai penyokong kebijakan, bukan sebagai penentu kebijakan, di mana para imam dan raib menjadikannya sebagai alasan utama dalam setiap pengambilan keputusan. Artinya, mulai dari perpajakan, sistem ekonomi, hingga persoalan-persoalan lingkungan, para pemimpin religius justru mengambil teori-teori dari sains modern, bukan ayat-ayat kitab suci. Bagi Harari, klaim ayat-ayat suci dalam agama hanya memainkan peran sebagai biola kedua (peran asisten) dari teori-teori sains modern yang mereka diadopsi. ${ }^{11}$

Ketika Khomeini perlu membuat sebuah pertimbangan penting tentang ekonomi Arab Saudi dengan m2enaikkan suku bunga, membuka peluang industri dan pasar keuangan global, ia tidak mungkin menemukannya dalam kitab suci. Melainkan menyandarkan pilihan-pilihannya pada Karl Marx, Milton Friedman, Friedrich Hayek, dan sains ekonomi modern untuk mendapatkan jawaban. Namun Khomeini tentu saja tidak serta merta melepaskan Islam. Al-Quran yang suci juga sebenarnya memuat gagasan tentang ekonomi, meliputi keadilan (Qs. 55: 7; Qs. 82: 7) dan kesetaraan (Qs. 16: 97; Qs. 6: 165; Qs. 7: 172). Tetapi argumentasi yang diberikan kitab suci tidak begitu mutakhir dalam menyelesaikan kompleksitas persoalan manusia. ${ }^{12}$

Ketiga, agama memuat problem identitas yang cukup akut. Selama ini, semua agama-agama tradisional hadir dengan corak dan warna yang berbeda. Dekorasi warnawarna itu lalu tercermin dalam ajaran dan hukum, yang kemudian memungkinkan masyarakat menjadi berbeda dalam memandang realitas satu sama lain. Di dalam dunia yang bergerak maju, problem identitas tidak lagi menjadi begitu penting. Masyarakat abad 21 dituntut untuk menjadi lebih cerdas dalam menciptakan kerja sama di antara mereka jika ingin bertahan. "Ide tentang sifat alami atau kodrat universal manusia membawa kita pada tema ketiga, humanisme", kata Steven Pinker. ${ }^{13}$ Dan humanisme, sampai kapanpun menggenggam prinsip bahwa tidak ada manusia yang patut diperlakukan secara istimewa. Untuk itulah gagasan agama dirasa menjadi alasan yang membelah masyarakat, membuatnya terkotak-kotak.

"Jadi", menurut Harari, "agama pada abad ke 21 tidak lagi membuat hujan, atau menyembuhkan penyakit, melainkan menentukan siapa kita dan siapa mereka". ${ }^{14}$ Alihalih dunia sedang bergerak menuju kosmopolitanisme, agama-lewat para fundamentalis-justru membuat jurang yang memisahkan para pemeluknya. ${ }^{15}$ Dalam

${ }^{11}$ Yuval Noah Harari, 21 Lessons, h. 141.

12 Ibid, h. 142.

13 Steven Pinker, Enlightenment Now: Membela Nalar, Sains, Humanisme, dan Kemajuan, (Manado: Penerbit Globalindo, 2019), h. 14.

14 Yuval Noah Harari, 21 Lessons, h. 140

15 Sigmund Freud, Totem and Taboo: Some Points of Agreement between the Mental Lives of Savages and Neurotics, (London: WW Norton, 1989), h. 89. 
hal lain bisa dilihat misalnya: tidak ada yang membedakan antara Kristen di Eropa, Hindu di India, Budha di Myanmar, atau Islam Sunni di Arab, dan Islam Syiah yang ada di Iran. Mereka adalah sekumpulan orang-orang yang hadir di tengah-tengah dunia yang terus berubah, di dalam masyarakat yang lebih mengharapkan adanya kejelasan dibanding imajinasi yang membelah komunitas manusia menjadi berkubu-kubu. Alhasil, pemaksaan identitas ujung-ujungnya justru menjadikan agama (lewat para pemeluknya) melakukan keburukan, dan membuat orang berperilaku bengis dan kejam.

Isu-isu terror yang mencekam adalah hasil dari problem identitas yang dilepaskan para fundamentalis. Ini juga bukti bahwa masyarakat beragama, masih belum mampu mengorganisir diri. Padahal sebenarnya terorisme tidak lebih begitu menakutkan dari kecelakaan lalu lintas 80.000 orang Eropa; diabetes dan kadar gula tinggi membunuh 3.5 juta orang pertahun, dan polusi udara yang membunuh sekitar 7 juta orang pertahun. ${ }^{16}$ Steven Pinker menggambarkan hal tersebut dengan begitu menarik, bahwa "terorisme sebenarnya adalah aksi kejahatan yang menyebabkan sedikit korban, namun dengan hysteria yang begitu besar" ${ }^{17}$ Tujuan aksi-aksi terror ${ }^{18}$ sebenarnya bukan banyaknya korban yang berjatuhan, melainkan ketakutan yang dapat dihasilkannya. Sehingga, kita diharapkan agar tidak panik, terus mawas diri, dan saling menguatkan.

\section{Teologi Natural: Dari Materialisme menuju Spiritualitas Saintifik}

Jika sains telah berkembang secara signifikan, apakah Tuhan, manusia, dan alam semesta benar-benar tak punya masa depan di abad 21? Saya kira juga tidak. Bagi saya, sains hanya belum menemukan bahasa yang tepat untuk digunakan pada beberapa terminologi agama. Ian G. Barbour (1923-2013), fisikawan sohor asal Carleton College, AS, sadar akan hal itu. Oleh karenanya, Barbour terus berupaya memetakkan hubungan

${ }_{16}$ World Health Organization, 'Deaths on the Roads: Based on the WHO Global Status Report on Road Safety 2015'; About Multiple Cause of Death, 1999-2016', Centers for Disease Control and Prevention, https://wonder.cdc.gov/mcd-icd10.html, diakses 22 April 2016; World Healt Organization, 'Global Status Report on The Challenge of Diabetes,' www.euro.who.int/en/healthtopics/noncommunicable-disease/diabetes/data-and/statistics, diakses pada 22 April 2019; Adam Vaughan, 'China Tops WHO List for Deadly Outdoor Air Pollution,' Guardian, 27 September 2016.

${ }_{17}$ Steven Pinker, Enlightenment Now, h. 255.

18 Terorisme adalah puncak aksi kekerasan, terrorism is the apex of violence. Bisa saja kekerasan terjadi tanpa teror, tetapi tidak ada teror tanpa kekerasan. Terorisme tidak sama dengan intimidasi atau sabotase. Sasaran intimidasi dan sabotase umumnya langsung, sedangkan terorisme tidak. Korban tindakan Terorisme seringkali adalah orang yang tidak bersalah. Kaum teroris bermaksud ingin menciptakan sensasi agar masyarakat luas memperhatikan apa yang mereka perjuangkan. Dua tragedi terror yang terjadi pada awal tahun 2019 ini: pertama, penembakan di sebuah masjid yang berada di Kota Christchurch, Selandia Baru, pada tanggal 15 Maret 2019, dengan korban umat Islam tewas sebanyak 50 orang, dan lainnya luka-luka. Konon, Brenton Tarrant, seorang pelaku kejadian melakukan penembakan brutal itu secara live. Kedua, yang terjadi pada tanggal 21 April 2019, tepat di Hari Paskah, pengeboman terjadi di salah satu gereja terbesar yang berada di sekitaran hotel di, Kolombo, Sri Lanka yang telah merenggut 207 orang, serta 450 lainnya terluka. 
antara sains dan agama. Setidaknya ada empat varian yang ia temukan: konflik, independensi, dialog, dan integrasi. Dalam hubungan konflik, sains menegasikan eksistensi agama dan agama menegasikan sains. Keduanya sama-sama mengukuhkan eksistensi diri. Sementara itu, di dalam hubungan independensi; masing-agama dan sains masing-masing mengakui keabsahannya, sebab keduanya memang berurusan pada ranah yang berbeda. Klaim kebenaran yang didasarkan pada keduanya pun berbeda. Alhasil hubungan ini memungkinkan tidak ada irisan di antara sains dan agama. ${ }^{19}$

Hubungan dialog justru lebih eklektik: memungkinkan adanya interaksi antara sains dan agama dengan perbandingan metode-metode dari dua bidang itu. Di dalam dialog, ada harapan agar sains dan agama menemukan jalan yang sama. Misalnya, dalam mengungkap sesuatu yang tidak dapat diamati secara langsung dalam agama, digunakanlah konsep atau analogi-analogi yang merepresentasikan hal-hal tersebut. Sedang dalam hubungan integratif (Barbour secara spesifik memilih hubungan ini), adalah mengupayakan suatu integrasi yang lebih sistematik antara ilmu pengetahuan dan agama dengan harapan agar adanya temuan bukti (atau setidaknya yang lebih mendekati) akan eksistensi Tuhan. Barbour lalu menyebut ide ini dengan "Teologi Natural".20

Meskipun Barbour melandasi gagasannya hanya pada agama Kristen, kita dapat melihat bahwa upaya yang dilakukannya begitu berharga dalam dunia sains dan agama. Teologi natural lalu disandarkan pada konsep filosofis Whiteheadian ${ }^{21}$ bahwa setiap subjek itu terus menerus "menjadi" (becoming), ketimbang "berada" (being); perubahan ketimbang persistensi; dan peristiwa-dan-proses ketimbang substansi. ${ }^{22}$ Mengingat substansi dalam setiap objek sebenarnya sama, hanya saja diutarakan dalam konteks yang berbeda. Whitehead lantas menyimpulkan bahwa komponen realitas dasar itu sebenarnya tidak abadi, melainkan setiap diiringi oleh peristiwa yang terus menjadi secara kreatif menuju masa depan. Alhasil, varian teologi natural akhirnya keluar dengan jawaban: "Dengan tidak melepaskan inti, pemahaman keagamaan perlu diletakkan secara kontekstual, diubah, dan disesuaikan dengan penemuan-penemuan mutakhir". ${ }^{23}$

19 Ian G. Barbour, Menemukan Tuhan dalam Sains Kontemporer, (Mizan: Bandung, 2005), h. 33 .

${ }^{20} \mathrm{Ibid}$, h. 34.

${ }^{21}$ Whiteheadian adalah salah satu term yang digunakan untuk merujuk pemikiran seorang filsuf yakni Alfred North Whitehead, OM (lahir di Ramsgate, Kent, Inggris, 15 Februari 1861-meninggal di Amerika Serikat, 30 Desember 1947 pada umur 86 tahun) adalah seorang matematikawan Inggris yang menjadi seorang filsuf. Gagasan-gagasan Whitehead banyak dipengaruhi oleh Henry Bergson, William James, dan John Dewey. Whitehead dikenal karena ia berhasil merumuskan filsafat proses-salah satu bentuk filsafat yang memungkinkan adanya titik temu antara agama dan sains. Ia menulis tentang aljabar, logika, dasar matematika, filosofi ilmu pengetahuan, fisika, metafisika dan pendidikan.

22 Alfred North Whitehead, Process and Reality, (New York: The Free Press, 1978), p. 39.

23 Ian G. Barbour, Menemukan Tuhan h. 171. 
Sayang, Barbour tidak menjelaskan dengan jernih apa makna "substansi" yang dimaksudnya. Apakah itu hukum-hukum gereja, ayat-ayat suci, ataukah perintahperintah para raib? Adalah Muhammad Iqbal (1877-1938), seorang penyair Muslim dan filsuf Islam terbesar abad ke 19 yang bagi saya, berhasil meruntuhkan bias itu. Iqbal tidak pernah bertemu dengan Barbour, dan justru lebih dulu lahir darinya. Namun pandangan Iqbal-yang juga dipengaruhi oleh Whitehead-begitu komplementer dan memiliki pengaruh besar terhadap pengetahuan dan agama. Menurutnya, substansi yang tidak bisa dilepaskan dari agama adalah iman. Sebab di dalamnya ada kandungan kognitif yang memungkinkan segala sesuatu bisa dicandra secara rasional. ${ }^{24}$. Iqbal lalu memperjelas argumentasinya dengan menyatakan:

"Agama berbicara dalam skala yang lebih luas, bukan sekadar perasaan, dan bukan juga sekadar tindakan. Agama adalah ungkapan manusia secara utuh. Dengan demikian, agama harus diakui sebagai titik pusat dalam proses sintesisreflektif." 25

Substansi yang disebut Iqbal adalah keimanan. Baginya, pengetahuan boleh saja berkembang sejauh mungkin. Namun jalannya harus tetap senantiasa diterangi cahaya agama, cahaya keimanan. Sebab agama juga memiliki kandungan emosional yang memproduksi kekuatan spiritual setiap manusia. "Sains", sebagaimana diungkap oleh Deepak Chopra, "akan menjadi begitu kering tanpa cahaya Agama". ${ }^{26}$ Dan keadaan itu hanya akan terjadi apabila pemeluk agama terus mawas diri dan melek terhadap perubahan. Bersama sains, keduanya akan menjadi sahabat baik. Namun dengan pikiran yang kaku dan eksklusif, sains dan agama akan terus membakar. Pendekatan sintesis-reflektif memungkinkan terjadinya sebuah keadaan yang saya sebut sebagai "spiritualitas-saintifik": suasana takjub, bahkan membenamkan diri dalam keagungan dan kegemilangan ketika manusia dapat mengetahui bukti-bukti ketersingkapan alam semesta dan perubahan-perubahan yang dimilikinya.

Dengan demikian, perubahan-perubahan tertentu dalam agama adalah sebuah keharusan. Kita mesti menerimanya. Iman tetap tinggal. Iman yang semestinya tetap tidak berubah. Beberapa fundamentalis dalam Islam tidak mengakui ini. Mereka tetap teguh bahwa kehidupan modern-dengan seluruh perubahan saintifiknya-hanya akan membuat ajaran-ajaran agama menjadi tereduksi. Padahal dalam Islam, salah satu sifat al-Quran adalah Shahih fii Kulli Zamaan wa Makaan-sesuai dengan setiap konteks

24 Muhammad Iqbal, Rekonstruksi Pemikiran Religius dalam Islam, (Bandung: Mizan, 2016), h.

3 .

25 Ibid, h. 3.

26 Deepak Chopra, The Future of God: Pendekatan Praktis Menuju Spiritualitas Masa Kini, (Jakarta Selatan: Zaituna Ufuk Abadi, 2016), h. 19. 
zaman dan waktu. Melalui hasil ijtima', hukum-hukum Islam sebisa mungkin direkonstruksi kembali untuk menjawab segala tantangan zaman. ${ }^{27}$

Keterbukaan pandangan seseorang tentang sesuatu, adalah sains sebagai "cara berpikir", yang oleh Carl Sagan bersifat imajinatif sekaligus berdisiplin. ${ }^{28}$ Dengan pengumpulan, pemetaan, penggabungan; ketika manusia berjumpa dengan alam semesta, ia akan senantiasa menimbulkan rasa hormat dan kekaguman. Sesuatu yang merupakan cakupan visi spiritual tentang kesyukuran manusia terhadap ciptaan agung-yang dalam klaim agama "diciptakan oleh Kreator Agung, Tuhan, Allah". Meskipun sains mungkin sampai kapanpun tidak akan pernah mengakui adanya Penggerak Mutlak dibalik terbentangnya alam semesta beserta seluruh keteraturannya.

Dengan perasaan yang begitu kuat, sains sebenarnya telah memberikan semacam kekuatan pada manusia untuk mengisi ruang-ruang spiritual mereka-yang begitu erat kaitannya dengan setiap agama, dan memang hanya agama yang menggunakan kata spiritual dalam setiap ajarannya. Perlu disadari bahwa realitas selalu berubah, zamanzaman yang berganti, pemahaman masyarakat begitu maju, yang akhirnya melepaskan semacam kerumitan, indah, kehalusan. Lalu, dari dalam kondisi itu; ada semacam kekuatan yang membuncah dalam diri. Perasaan apa itu jika bukan spritualitas? Itu sebabnya, sains bukan hanya cocok dengan agama, melainkan ia juga merupakan sumber penting agama.

\section{Kesimpulan}

Sejak memasuki imperium ke III, abad ke 21, pertikaian antara agama dan sains tidak pernah selesai. Justru, setelah temuan-temuan sains menjadi semakin mutakhir, beberapa saintis menyatakan bahwa agama adalah salah satu variabel penghambat majunya sebuah peradaban. Salah satu yang paling mutakhir mengkritik perkembangan ini adalah Richard Dawkins, Yuval Noah Harari dan Jared Diamond. Namun, di antara mereka, justru ada beberapa saintis seperti Deepak Chopra dan Carl Sagan yang menjelaskan bahwa kedua variabel penting ini justru saling topang dan tidak terpisahkan. Ian G. Barbour, salah seorang saintis di akhir abad ke 21 menganggap bahwa sains dan agama yang bisa didialogkan jika keduanya membuka lebar ruang-

${ }_{27}$ Dahulu, masyarakat Muslim begitu kaku menyikapi adanya jual-beli melalui dunia maya, sebab ditakutkan akan mereduksi hukum jual-beli sesuai syariat (Bertemunya penjual dan pembeli, jelasnya barang dan akad jual beli). Namun hari ini, dengan terang kita melihat hal-hal itu berubah. Bahtsul Masail Muktamar NU ke-32 di Makasar tahun 2010 dalam hal ini, adapun jawabannya adalah bahwasannya Hukum akad (transaksi) jual beli melalui alat elektronik sah, apabila sebelum transaksi kedua belah pihak sudah melihat mabi' (barang yang diperjualbelikan) atau telah dijelaskan baik sifat maupun jenisnya, serta memenuhi syarat-syarat dan rukun-rukun jual beli lainnya dengan dasar pengambilan hukum. Ketetapan hukum ini dilandasi hasil pembacaan kritis terhadap kitab Syarh alYaqut an-Nafis karya Muhammad bin Ahmad al-Syatiri dan Nihayah al-Muhtaj ila Syarh alMinhaj karya Syihabuddin Ar-Raml.

${ }^{28}$ Carl Sagan, The Demon Haunted World, h. 35. 
ruang untuk berdialog dan tidak menjadi eksklusif. Selain itu, Iqbal, seorang penyair dan filsuf kebangsaan Pakistan menyebut bahwa agama dan sains adalah cahaya penerang sebuah peradaban. Dengan mengembangkan model teologi, yakni "Natural Theology"-dengan sentuhan Whitehead-diperoleh fakta bahwa sains dan agama sama-sama memiliki visi yang sama, yakni memberikan perasaan spiritual terhadap manusia.

\section{Daftar Pustaka}

Amin, Basri. Memory Gorontalo: Teritori, Transisi dan Tradisi. Yogyakarta: Penerbit Ombak, 2012.

Armstrong, Karen. Sejarah Tuhan: Kisah Pencarian 4000 Tahun Agama-agama Dunia. Bandung: Mizan. 2015.

Barbour, Ian G. Menemukan Tuhan dalam Sains Kontemporer. Bandung: Mizan. 2005.

Chopak, Deepak. The Future of God: Pendekatan Praktis Menuju Spiritualitas Masa Kini. Jakarta Selatan: Zaituna Ufuk Abadi, 2016.

Freud, Sigmund. Totem and Taboo: Some Points of Agreement between the Mental Lives of Savages and Neurotics. London: WW Norton. 1989.

Fuller, E. Graham. Dunia Tanpa Islam: Apa Jadinya Dunia Tanpa Islam? Sebuah Narasi Sejarah Alternatif. Bandung: Mizan, 2014.

Hamka Hendra Noer, dkk. Menggagas Masa Depan Gorontalo. Yogyakarta: HPMIG Press. 2005.

Harari, Yuval Noah. 21 Lessons: 21 Adab Untuk Abad ke 21. Globalindo: Manado, 2018.

Iqbal, Muhammad Rekonstruksi Pemikiran Religius dalam Islam. Bandung: Mizan. 2017.

Katili, John Ario \& Marks. P. Geologi. Jakarta: Departemen Urusan Riset Nasional. 1963.

Katili, John Ario. Rubrik Tokoh. Buletin Sumberdaya Geologi Vol. 3 tahun 2008. . Harta Bumi Indonesia: Biografi John Ario Katili. Jakarta: PT. Grasindo Pustaka. 2007.

Mazhar, Armahedi. 2005. Manusia, Alam dan Tuhan: Menyepadukan Sains dan Agama, sebuah pengantar dalam buku "Ian G. Barbour: Menemukan Tuhan dalam Sains Kontemporer", Bandung: Mizan, 2005.

Nasr, Seyyed Hossein. The Heart of Islam: Pesan-pesan Universal Islam terhadap Kemanusiaan. Bandung: Mizan. 2001.

Niode, S. Alim. Gorontalo; Perubahan Nilai-nilai Budaya dan Pranata Sosial. Cet. I; Jakarta: Pustaka Indonesia Press. 2007.

Pinker, Steven. Enlightenment Now (Pencerahan Sekarang Juga): Membela Nalar, Sains, Humanisme, dan Kemajuan. Manado: Penerbit Globalindo. 2019.

Polontalo, Ibrahim. Adat Bersendikan Syara, Syara Bersendikan Kitabulah Sebagai Dasar Pengembangan Budaya dan Pelaksanaan Islam di Gorontalo. dalam sebuah makalah pada Seminar Nasional BPKI-KTI di Gorontalo. 2003.

Rouf, Abdul Mukti. Kritik Nalar Arab Muhammad Abid al-Jabiri. Yogyakarta: LP3ES, 2018.

Sagan, Carl. The Demon Haunted World: Sains Penerang Kegelapan. Jakarta: Kepustakaan Populer Gramedia. 2018.

Vaughan, Adam. 'China Tops WHO List for Deadly Outdoor Air Pollution,' Guardian, 27 September 2016. 
Whitehead, Alfred North. Process and Reality. New York: The Free Press. 1978.

Wijaya, Aksin. Dari Membela Tuhan ke Membela Manusia: Kritik Atas Agamaisasi Kekerasan. Bandung: Mizan. 2018.

World Health Organization, 'Deaths on the Roads: Based on the WHO Global Status Report on Road Safety 2015'; About Multiple Cause of Death, 1999-2016', Centers for Disease Control and Prevention, https://wonder.cdc.gov/mcdicd10.html.

World Health Organization, 'Global Status Report on The Challenge of Diabetes,' www.euro.who.int/en/health-topics/noncommunicable-disease/diabetes/dataand/statistics. 